\title{
Patterns of dental visits and their predictors among male adolescents
}

\section{Częstotliwość i czynniki prognostyczne wizyt w gabinecie stomatologicznym wśród nastolatków płci męskiej}

\author{
Muhammad Ashraf Nazir ${ }^{A-F}$ \\ College of Dentistry, Imam Abdulrahman Bin Faisal University, Dammam, Saudi Arabia \\ A - research concept and design; $B$ - collection and/or assembly of data; $C$ - data analysis and interpretation; \\ $D$ - writing the article; $\mathrm{E}$ - critical revision of the article; $\mathrm{F}$ - final approval of the article
}

Address for correspondence

Muhammad Ashraf Nazir

E-mail: manazir@iau.edu.sa

Funding sources

None declared

Conflict of interest

None declared

Received on January 23,2018

Reviewed on February 10, 2018

Accepted on March 17, 2018
DOI

$10.17219 / \mathrm{dmp} / 87023$

Copyright

(C) 2018 by Wroclaw Medical University

and Polish Dental Society

This is an article distributed under the terms of the

Creative Commons Attribution Non-Commercial License

(http://creativecommons.org/licenses/by-nc-nd/4.0/)

\begin{abstract}
Background. Improved oral health outcomes, including better quality of life, are associated with dental attendance. Visiting a dental office is an important mode of behavior, especially among adolescents; however, the factors that influence the patterns of dental visits are not fully understood.

Objectives. The objective of this study was to investigate the frequency of visiting a dental office and its predictors among male adolescents.
\end{abstract}

Material and methods. This cross-sectional study involved a sample of 376 male adolescents (13-14 years old). Multi-stage random sampling was used to recruit participants from public schools in Dammam, Saudi Arabia. World Health Organization (WHO) oral health questionnaire for children was used for data collection. The $x^{2}$ test and multiple logistic regression analyses were performed to investigate the predictors of dental attendance.

Results. Fifty-one percent of studied adolescents $(n=192)$ visited the dentist during the last 12 months. Pain was the most common reason for the dental visit (22.9\%), followed by a treatment or a follow-up (16.2\%), and a routine dental check-up (9.3\%). The participants with pain were 16.29 times more likely to visit a dental office than those without pain. Similarly, adolescents who had routine dental check-ups (odds ratio $(O R)=7.54,95 \%$ confidence interval $(C I)=3.75,15.15)$ and treatment or follow-ups had significantly higher odds (OR $=15.21,95 \% \mathrm{Cl}=7.22,32.04)$ of making a dental visit than those without check-ups and treatment. In addition, the perception of good health of gums $(0 \mathrm{R}=2.49,95 \% \mathrm{Cl}=1.33,4.66)$ and difficulty in chewing $(O R=2.00,95 \% \mathrm{Cl}=1.02,3.92)$ were associated with dental attendance.

Conclusions. Visiting a dental office was common among male adolescents. Pain was the most important reason and a predictor for dental attendance, and a small proportion of adolescents made dental visits for routine dental check-ups. Oral health literacy should be improved through awareness programs in schools. Adolescents should be encouraged to regularly visit the dentist to maintain optimal oral health.

Key words: adolescents, dental pain, dental visits, dental check-up

Słowa kluczowe: młodzież, ból zębów, wizyty u stomatologa, kontrola dentystyczna 
Visiting a dental office is associated with improved oral health (reduced caries experience and tooth loss) and better quality of life. ${ }^{1,2}$ It has been found that regular dental visits in children can result in positive oral health outcomes in adulthood. ${ }^{3}$ The prevalence of untreated caries in at least 1 permanent molar was 20\% in children aged 12-19 years. ${ }^{4}$ Data from the third National Health and Nutrition Examination Survey (NHANES III) showed that the prevalence of untreated caries in at least 1 permanent molar was $20 \%$ in children aged 12-19 years in the USA. In addition, the cost of dental treatment in children (5-17 years old) was approx. $\$ 20$ billion in 2009 in the USA. ${ }^{5}$ Teenagers were reported to have the highest unmet oral care needs and they had the least annual dental visits in addition to reduced dental service utilization. ${ }^{6,7}$ Moreover, it has been shown that $32 \%$ of adolescents did not have a dental examination during the last 12 months in the USA. ${ }^{8}$

The majority of adolescents avoid seeking healthcare advice on the conditions that could cause disability or even death among them, despite the presence of risky behaviors, systemic diseases and poor health during adolescence. ${ }^{9}$ It was found that $1 / 3$ of adolescents (13-17 years old) made no preventive visits during the 4 years of enrollment in a healthcare plan. ${ }^{10}$ Preventive dental visits are effective in reducing the burden of oral disease, however, the utilization of oral care was low, as only $14.2 \%$ of children received topical fluoride and/ or dental sealants. ${ }^{4}$ It was observed that preventive dental visits in children were related to family income, the educational level of the head of the family and the type of insurance.5,11 Gender, smoking behavior and parental dental visiting patterns were also associated with dental attendance in adolescents. ${ }^{12}$ Furthermore, an individual's income level and the degree of pain experienced determine visiting a dental office. ${ }^{13}$

The concept of "dental home" was promoted to provide preventive oral care to children according to the values of family. ${ }^{14}$ There has been a lot of emphasis on dental attendance in preschool children, as an early dental visit is suggested for the prevention of oral diseases before their occurrence and should be made when a child is 1 year of age. ${ }^{5}$ Although a significant burden of oral disease exists in adolescents, in addition to poor oral and systemic health as well as their risky health-related behaviors, little is known about the pattern of dental visits among them. Similarly, there is a high prevalence of oral diseases among adolescents in Saudi Arabia and evidence is scant about dental attendance in Saudi schoolchildren. ${ }^{15}$ The objective of the study, therefore, is to assess the pattern of dental visits and associated factors among male Saudi schoolchildren.

\section{Material and methods}

This cross-sectional study employed an estimated sample of 430 male schoolchildren aged $13-15$ years. The sample calculation was based on the approximate population size of male students in Dammam, Saudi Arabia, $5 \%$ confidence limit, hypothesized frequency of outcome factor in the population, and design effect (Sample size $n=[\operatorname{DEFF} * N p(1-\mathrm{p})] /\left[\left(\mathrm{d}^{2} / \mathrm{Z}_{1-\alpha / 2}^{2}{ }^{*}(\mathrm{~N}-1)+\mathrm{p}^{*}(1-\mathrm{p})\right]\right)$. The students were recruited using multi-stage sampling technique from public schools in Dammam, Al-Khobar and Dhahran, Saudi Arabia. World Health Organization (WHO) oral health questionnaire for children was used for data collection. ${ }^{16}$ The self-completed questionnaire was translated into Arabic. The study was explained to the participants and informed consent was obtained from them before the administration of the research tool. The right to voluntarily participate in the study was also discussed with the respondents. They were ensured about preserving the anonymity of their responses. Ethical guidelines were followed during the data collection, reporting and the publication of information.

The respondents were asked to provide information about the frequency and reasons for their dental visits, oral hygiene practices, including the use of fluoridated toothpaste, the experience of oral problems during the past 12 months, and educational attainment of parents. The data was collected as a part of an internship research project at the College of Dentistry, Imam Abdulrahman Bin Faisal University, Dammam, Saudi Arabia, and partial data was analyzed to report the patterns of dental attendance among adolescents.

The descriptive and inferential statistics were calculated using SPSS Statistics for Windows, v. 22.0 (IBM Corp., Armonk, USA). The students' responses were dichotomized to calculate odds ratio (OR). Pearson's $\chi^{2}$ test was performed to calculate unadjusted ORs of the education of parents, reasons for visiting a dental office, difficulty in biting and chewing, use of toothpaste, and perceived health of gums and teeth, with visiting the dentist. Binary logistic regression was performed to observe the association between different variables of the study and dental attendance after controlling for other factors. A stepwise forward selection method was used for building the final logistic regression "best" model. A 95\% confidence interval $(\mathrm{CI})$ and a p-value $<0.05$ were used for determining statistical significance.

\section{Results}

Out of the 430 questionnaires distributed, 376 were entered in the statistical analysis. The mean age of the participants was 14.3 years \pm standard deviation (SD) 0.051. The majority of the students had parents with secondary school education or higher. More than 2/3 
of the students perceived the health of their gums and teeth as good. Half of the members of the sample (51.1\%) visited the dentist during the last 12 months. Eighty-six respondents $(22.9 \%)$ indicated that they had visited a dental office during the last 12 months due to pain or problems with teeth or gums, and this was the most common reason for dental attendance. The second most common reason was dental treatment or a follow-up $(16.2 \%, \mathrm{n}=61)$, followed by a routine dental check-up (9.3\%, $\mathrm{n}=35)$. The majority of respondents $(88.3 \%)$ said they used toothpaste to clean their teeth; however, only $18.1 \%$ were aware of using fluoridated toothpaste. More students had difficulty in chewing

Table 1. Distribution of responses of study participants

\begin{tabular}{|lc|}
\multicolumn{1}{|c|}{ Variables } & Percentage $(95 \% \mathrm{CI})$ \\
\hline Prevalence of visiting the dentist & $51.1(46,56.1)$ \\
Reasons of dental visits & \\
$\quad$ pain or trouble with teeth, gums or mouth & $22.9(18.9,27.4)$ \\
$\quad$ treatment/follow-up & $16.2(12.8,20.3)$ \\
$\quad$ routine check-up & $9.3(6.8,12.7)$ \\
Mother's education & \\
$\quad \geq$ secondary school education & $65.4(60,70)$ \\
$\quad$ sprimary school education & $34.6(29.9,39.5)$ \\
Father's education & \\
$\quad \geq$ secondary school education & $76.9(72,81)$ \\
$\quad$ primary school education & $23.1(19,27.6)$ \\
Difficulty in biting food & $9.8(7.2,13.3)$ \\
Difficulty in chewing food & $18.1(14.5,22.3)$ \\
Cleaning teeth & $89.4(85.8,92.1)$ \\
Use of fluoridated toothpaste & $18.1(14.5,22.3)$ \\
Use of toothpaste & $88.3(84.7,91.2)$ \\
Dissatisfaction with appearance & $48.9(43.9,54)$ \\
Perceived health of gums & $78.7(74.3,82.6)$ \\
Perceived health of teeth & $84(80.3,87.7)$ \\
\hline
\end{tabular}

$\mathrm{Cl}$ - confidence interval.
(18.1\%) than problems with biting the food (9.8\%), although these percentages were low. Considerable proportions of mothers and fathers had secondary school education (Table 1).

Figure 1 shows the frequency of dental visits among the respondents during the last 12 months. It can be seen that a small percentage (16.2\%) visited the dentist once a year. Thirty-eight percent of the respondents either did not visit a dental office during the last 12 months or had never received dental care/visited the dentist.

Unadjusted ORs were calculated to observe the association between different variables of the study and visiting the dentist. The participants who had difficulty in chewing and were aware that they used fluoridated toothpaste were more likely to visit the dentist than those with no difficulty in chewing or who were unaware of using fluoridated toothpaste. Similarly, dental pain, treatment/ follow-up, routine dental check-up and perceived good health of gums were significantly associated with visiting the dentist. After controlling for other variables of the study, dental pain (0.001), treatment/follow-up (0.001), routine dental check-up (0.001), use of fluoridated toothpaste (0.023), and self-perceived good health of gums (0.001) remained significant predictors of a dental visit (Table 2).

With the best predictive power, final logistic regression model using a forward method revealed that the participants with dental pain were 16.29 times more likely (0.001) to visit the dentist than those without pain. Similarly, the respondents who needed dental treatment or had a follow-up visit had higher odds $(\mathrm{OR}=15.21$, 0.001) of visiting the dentist than those who did not require treatment or follow-up. Other significant predictors of dental visits included routine dental checkup $(\mathrm{OR}=7.54,0.001)$, perceived good health of gums $(\mathrm{OR}=2.49,0.022)$ and difficulty in chewing $(\mathrm{OR}=2.00$, 0.042) (Table 3).

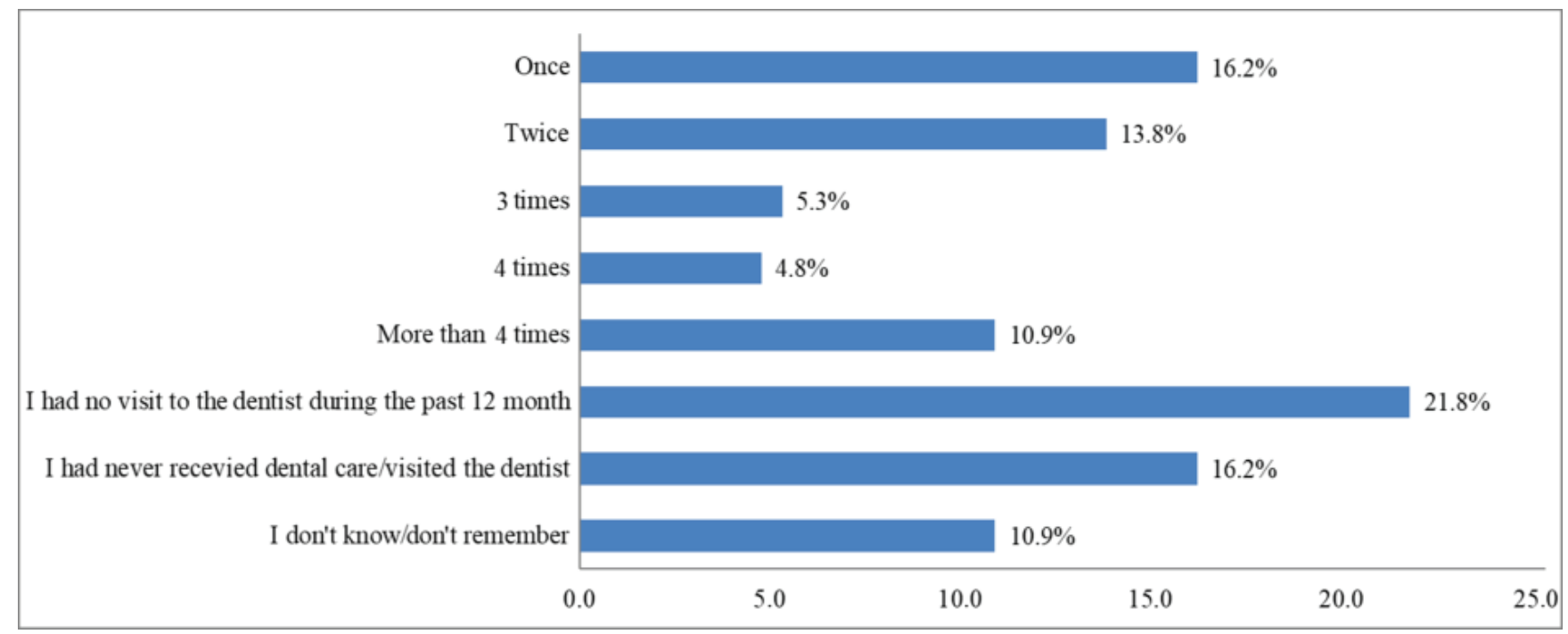

Fig. 1. Frequency of dental visits among adolescents during the past 12 months 
Table 2. Factors associated with visiting the dentist among adolescents

\begin{tabular}{|c|c|c|c|c|}
\hline \multirow{2}{*}{ Variables } & \multicolumn{2}{|c|}{ Unadjusted OR } & \multicolumn{2}{|c|}{ Adjusted OR } \\
\hline & OR $(95 \% \mathrm{Cl})$ & p-value & OR $(95 \% \mathrm{Cl})$ & p-value \\
\hline Mother's education $\geq$ secondary school education vs $\leq$ primary school education & $1.25(0.83,1.88)$ & 0.83 & $1.11(0.59,2.09)$ & 0.60 \\
\hline Father's education $\geq$ secondary school education vs $\leq$ primary school education & $1.173(0.76,1.80)$ & 0.90 & $0.52(0.25,1.0)$ & 0.08 \\
\hline Difficulty in biting food & $1.80(0.92,3.81)$ & 0.08 & $1.15(0.39,3.35)$ & 0.97 \\
\hline Difficulty in chewing food & $1.98(1.14,3.42)^{*}$ & $0.016^{*}$ & $1.71(0.77,3.78)$ & 0.11 \\
\hline Never cleaned teeth & $0.95(0.49,1.83)$ & 1.00 & $1.47(0.48,4.53)$ & 0.65 \\
\hline Use of fluoridated toothpaste & $1.83(1.07,3.15)^{*}$ & $0.03^{*}$ & $2.17(1.09,4.32)^{*}$ & $0.02^{*}$ \\
\hline Use of toothpaste & $1.03(0.54,1.97)$ & 1.00 & $0.90(0.30,2.69)$ & 0.87 \\
\hline Dissatisfaction with appearance & $0.88(0.59,1.32)$ & 0.61 & $0.87(0.52,1.47)$ & 0.37 \\
\hline Dental pain & $6.61(3.61,12.09)^{*}$ & $0.001^{*}$ & $17.88(8.84,36.15)^{*}$ & $0.001^{*}$ \\
\hline Routine dental check-ups & $2.42(1.31,4.47)^{*}$ & $0.005^{*}$ & $8.59(4.11,17.98)^{*}$ & $0.001^{*}$ \\
\hline Dental treatment/follow-up & $4.91(2.51,9.59)^{*}$ & $0.001^{*}$ & $17.95(8.24,39.07)^{*}$ & $0.001^{*}$ \\
\hline Perceived health of gums & $2.15(1.29,3.59)^{*}$ & $0.004^{*}$ & $2.46(1.30,4.66)^{*}$ & $0.001^{*}$ \\
\hline Perceived health of teeth & $0.972(0.56,1.68)$ & 1.00 & $0.78(0.17,1.37)$ & 0.12 \\
\hline
\end{tabular}

$\mathrm{OR}$ - odds ratio; $\mathrm{Cl}$ - confidence interval; * statistically significant $\mathrm{p}<0.05$.

Table 3. Final logistic regression model: factors associated with visiting the dentist among adolescents

\begin{tabular}{|l|c|c|}
\multirow{2}{*}{\multicolumn{1}{c}{ Variables }} & \multicolumn{2}{c|}{ Adjusted OR } \\
\cline { 2 - 3 } Difficulty in chewing food & $2.00(1.02,3.92)^{*}$ & $0.04^{*}$ \\
Dental pain & $16.29(8.24,32.21)^{*}$ & $0.001^{*}$ \\
Routine dental check-ups & $7.54(3.75,15.15)^{*}$ & $0.001^{*}$ \\
Dental treatment/follow-up & $15.21(7.22,32.04)^{*}$ & $0.001^{*}$ \\
Perceived health of gums & $2.49(1.33,4.66)^{*}$ & $0.02^{*}$ \\
\hline
\end{tabular}

$\mathrm{OR}$ - odds ratio; $\mathrm{Cl}$ - confidence interval; * statistically significant $\mathrm{p}<0.05$.

\section{Discussion}

The present study documented that pain was the most common reason $(22.9 \%)$ for dental attendance and the strongest predictor $(\mathrm{OR}=16.2)$ of dental visits among teenagers. These findings are in accordance with the available body of evidence. Zhu et al. observed that $29 \%$ of Chinese teenagers (12 years old) visited the dentist because of pain or dental caries. ${ }^{17}$ A study of 12 -year-old children in Kuwait reported that $53 \%$ of the participants visited a dental office due to pain or problems with teeth or gums. ${ }^{18}$ Similarly, a nationwide survey of Jordanian schoolchildren (6-12 years old) found $83 \%$ of them visiting the dentist because of symptoms. ${ }^{19}$ However, children expressed esthetics/appearance as the major cause of dental visits in the USA. ${ }^{20} \mathrm{~A}$ high prevalence of dental caries (decayed, missing and filled teeth [DMFT] index $=3.34$ ) in permanent dentition of children aged 6-18 years in the Saudi Arabia could be a possible reason for dental pain or problems, and subsequent visits to the dentist. ${ }^{17,21}$

In Saudi Arabia, a previous study conducted in 1998 reported that $45 \%$ of children (6-12 years old) performed an annual dental visit in the city of Madina, while $51.1 \%$ children in the present study attended a dental office during the past 12 months in Dammam. ${ }^{22}$ It seems that over a period of 18 years, no comprehensive oral health awareness program for children has been successfully established and run in the country. In contrast, the patterns of dental visits among teenagers appear different in developed countries. The majority of children aged $11-15$ years (57.8\%) made a dental visit and $20.8 \%$ availed themselves of preventive dental care in the USA. ${ }^{5}$ In a survey of Australian teenagers (12-17 years old), $81.8 \%$ visited the dentist during the last year. ${ }^{23}$ Similarly, $79.9 \%$ and $84 \%$ of adolescents made dental visits during the past 12 months in New Zealand and Canada, respectively. ${ }^{24,25}$

The present study showed that $49 \%$ of Saudi children had never visited a dental office, which is close to the results of a study by Zhu et al., who found that $52.2 \%$ of Chinese children (12-18 years old) had never saw a dentist. ${ }^{17}$ On the other hand, a study of Nigerian children showed that $80 \%$ had never visited the dentist. ${ }^{26}$ However, data from National Longitudinal Study of Adolescent Health in the USA showed that $2 \%$ of adolescents had never had a dental examination. ${ }^{8}$ It is known that access to oral healthcare is related to social, economic and cultural dynamics in addition to the geographic distribution of populations and healthcare resources. However, many obstacles associated with these factors can be minimized by increasing oral health literacy, improving training of the dental workforce, and creating avenues and developing a policy framework for the provision of optimal oral care. ${ }^{27}$

Routine dental check-up was performed by $9.3 \%$ of the members of the sample in the present study, and they were 7.5 times more likely to visit the dentist than those who did not have regular check-ups during the last 12 months. These results are in agreement with the data shown by Davoglio et al., who reported that preventive treatment 
was the reason for visiting the dentist in $11.25 \%$ of Brazilian adolescents. ${ }^{28}$ Similarly, a small proportion (11\%) of Jordanian children visited the dentist for regular dental check-ups. ${ }^{19}$ One-third of Chinese children (35.2\%) made a dental visit for preventive dental check-ups during the last 2 years. ${ }^{17}$ However, the prevalence of dental visits for check-ups was $85.9 \%$ among teenagers (12-17 years old) in Australia. ${ }^{23}$ Sixty-two percent of adolescents in Britain made dental visits for examination without any symptoms. ${ }^{7}$ The most plausible explanation of the high prevalence of not receiving dental care and low percentage of children visiting the dentist for a check-up could be that there is lack of awareness about oral health, including the importance of visiting the dentist, among children and their parents in Saudi Arabia. There should be a national oral health awareness program to improve oral health of children through preventive measures, including emphasis on regular dental visits.

Low education of parents was associated with reduced dental visits, a decreased utilization of preventive services and a high prevalence of untreated dental caries among adolescents. ${ }^{4,5,29}$ It was found that the use of preventive medical care was related to parental education; however, annual dental visits had no association with the educational attainment of parents. ${ }^{30}$ Similar to those results, in the present study, both univariate and multivariate analyses revealed no significant association between parental education and dental attendance.

Our data analysis showed that children with perceived good health of gums were twice more likely to visit the dentist than those with poor gingival health. This result confirms the estimate reported by Lopez and Baelum, who observed that adolescents with poor oral health were twice more unlikely $(\mathrm{OR}=2.0)$ to make a dental visit during the last 12 months. ${ }^{29}$ Likewise, it was found that schoolchildren with a high prevalence of caries did not visit the dentist. ${ }^{26}$ This shows that there is a high prevalence of dental attendance among teenagers with improved oral health, and low self-esteem, shyness or embarrassment due to poor oral health could be the reason of low attendance to oral care, in addition to the presence of unmet dental care needs in our study. ${ }^{29,31}$ The use of fluoridated toothpaste is essential to maintaining optimal oral health, as it can help improve oral hygiene and prevent dental caries and periodontal disease. ${ }^{32}$ The children who were aware that they used fluoridated toothpaste were 2.5 times more likely to make a dental visit than those who did not know if they were using fluoride-containing toothpaste. Again, like in the case improved self-perceived well-being of gingival health, dentally aware children might frequently visit the dentist to maintain good oral health.

There is limited information available about the patterns of dental attendance among adolescents. Hence, our study provided valuable information about the frequency, reasons and predictors of dental visits. Healthcare policy makers and educators can utilize the findings of the study to improve the oral health of children. However, our study had a few weaknesses. Though it was anticipated that the inclusion of male students is not representative of teenagers in Dammam, data collection from female schools by male researchers was difficult due to culture norms in Saudi Arabia. Therefore, the data was unclear about the frequency and types of dental attendance among female adolescents. In addition, self-reported data can have some limitations; however, adolescents' responses have been shown to be valid. ${ }^{33}$ A future study should include a large sample of male and female students from public and private schools in urban and rural areas of the eastern province of Saudi Arabia. Given the importance of oral health and improving the access to oral care, particularly in children, conducting a national oral health survey should be the top priority of healthcare decision makers in the country.

\section{Conclusions}

In conclusion, this study showed that visiting the dentist was common among male schoolchildren in Saudi Arabia. Furthermore, pain was the most important reason for and the predictor of dental attendance, and a small proportion of schoolchildren visited the dentist for a routine dental check-up. The perception of healthy gums and the awareness of the use of fluoridated toothpaste were associated with increased chances of making dental visits. The findings of the study suggest that there is a high prevalence of oral diseases and low oral health literacy among teenagers. Developing policies, creating dental human resources with education and training, putting greater emphasis on prevention, establishing oral health awareness programs, and conducting national oral health survey will help improve the access to dental care and reduce the burden of oral disease. The importance of routine dental check-ups should be emphasized, and adolescents in particular should be encouraged to regularly visit the dentist to maintain optimal oral health.

\section{References}

1. McGrath C, Bedi R. Can dental attendance improve quality of life? Br Dent J. 2001;190:262-265.

2. Almoznino G, Aframian D, Sharav Y, et al. Lifestyle and dental attendance as predictors of oral health-related quality of life. Oral Dis. 2015;21:659-666.

3. Crocombe LA, Broadbent JM, Thomson WM, Brennan DS, Poulton R. Impact of dental visiting trajectory patterns on clinical oral health and oral health-related quality of life. J Public Health Dent. 2012;72:36-44.

4. Dye BA, Tan S, Smith V, et al. Trends in oral health status: United States, 1988-1994 and 1999-2004. Vital Health Stat. 2007;11:1-92.

5. Griffin SO, Barker LK, Wei L, et al. Use of dental care and effective preventive services in preventing tooth decay among U.S. children and adolescents: Medical Expenditure Panel Survey, United States, 2003-2009, and National Health and Nutrition Examination Survey, United States, 2005-2010. MMWR Suppl. 2014;63:54-60.

6. McBroome K, Damiano PC, Willard JC. Impact of the lowa S-SCHIP program on access to dental care for adolescents. Pediatr Dent. 2005;27:47-53. 
7. Hawley G, Holloway P, Davies R. Documented dental attendance patterns during childhood and adolescence. Br Dent J. 1996;180:145-148.

8. Stella MY, Bellamy HA, Schwalberg RH, Drum MA. Factors associated with use of preventive dental and health services among US adolescents. J Adolesc Health. 2001;29:395-405.

9. Ham P, Allen C. Adolescent health screening and counseling. Am Fam Physician. 2012;86:1109-1116.

10. Nordin JD, Solberg LI, Parker ED. Adolescent primary care visit patterns. Ann Fam Med. 2010;8:511-516.

11. Watson MR, Manski RJ, Macek MD. The impact of income on children's and adolescents' preventive dental visits. J Am Dent Assoc. 2001;132:1580-1587.

12. Attwood D, West $P$, Blinkhorn A. Factors associated with the dental visiting habits of adolescents in the west of Scotland. Community Dent Health. 1993;10:365-373.

13. Cohen LA, Bonito AJ, Eicheldinger $C$, et al. Behavioral and socioeconomic correlates of dental problem experience and patterns of health care-seeking. J Am Dent Assoc. 2011;142:137-149.

14. Nowak AJ, Casamassimo PS. The dental home: A primary care oral health concept. J Am Dent Assoc. 2002;133:93-98.

15. Al Agili D, Park H. Oral health status of male adolescent smokeless tobacco users in Saudi Arabia. East Mediterr Health J. 2013;19:711-719.

16. World Health Organization. Oral Health Surveys:BasicMethods. $5^{\text {th }}$ ed. World Health Organization; 2013.

17. Zhu L, Petersen PE, Wang HY, Bian JY, Zhang BX. Oral health knowledge, attitudes and behavior of children and adolescents in China. Int Dent J. 2003;53:289-298.

18. Vigild M, Petersen PE, Hadi R. Oral health behavior of 12-year-old children in Kuwait. Int J Paediatr Dent. 1999;9:23-29.

19. Rajab LD, Petersen PE, Bakaeen G, Hamdan MA. Oral health behavior of schoolchildren and parents in Jordan. Int J Paediatr Dent. 2002;12:168-176.

20. Dodd VJ, Logan H, Brown CD, Calderon A, Catalanotto F. Perceptions of oral health, preventive care and care-seeking behaviors among rural adolescents. J Sch Health. 2014;84:802-809.

21. Khan SQ, Khan NB, Arrejaie AS. Dental caries: A meta-analysis on a Saudi population. Saudi Med J. 2013;34:744-749.

22. Al-Tamimi S, Petersen PE. Oral health situation of schoolchildren, mothers and schoolteachers in Saudi Arabia. Int Dent $J$. 1998:48:180-186.

23. Harford J, Luzzi L. Child and Teenager Oral Health and Dental Visiting: Results From the National Dental Telephone Interview Survey 2010. Canberra, Australia: Australian Institute of Health and Welfare; 2013.

24. Ministry of Health of New Zealand. Our Oral Health: Key Findings of the 2009 New Zealand Oral Health Survey. Wellington, New Zealand: Ministry of Health of New Zealand; 2010.

25. Cooney P. Report on the Findings of the Oral Health Component of the Canadian Health Measures Survey 2007-2009. Ottawa, Canada: Publications Health Canada; 2010:1-111.

26. Adekoya-Sofowora CA, Nasir WO, Oginni AO, Taiwo M. Dental caries in 12-year-old suburban Nigerian school children. Afr Health Sci. 2006;6:145-150.

27. Institute of Medicine, National Research Council. Improving Access to Oral Health Care for Vulnerable and Underserved Populations. Washington, DC: The National Academies Press; 2011.

28. Davoglio RS, Abegg C, Aerts DR. Factors related to the use of dental services among adolescents from Gravatai, RS, Brazil, in 2005. Rev Bras Epidemiol. 2013;16:546-554.

29. Lopez R, Baelum V. Factors associated with dental attendance among adolescents in Santiago, Chile. BMC Oral Health. 2007;7:4. doi: 10.1186/1472-6831-7-4

30. Yu SM, Bellamy HA, Schwalberg RH, Drum MA. Factors associated with use of preventive dental and health services among US adolescents. J Adolesc Health. 2001;29:395-405.

31. Guarnizo-Herreño CC, Wehby GL. Children's dental health, school performance and psychosocial well-being. J Pediatr. 2012;161:1153-1159.

32. Löe H. Oral hygiene in the prevention of caries and periodontal disease. Int Dent J. 2000;50:129-139.

33. Silva AER, Menezes AMB, Assunção MCF, et al. Validation of self-reported information on dental caries in a birth cohort at 18 years of age. PLoS One. 2014;9. doi: 10.1371/journal.pone.0106382 